\title{
Factors Accounting for Differences of Fertility Desires and Intentions Among HIV-Infected and Uninfected Women of Reproductive Age at Six Hospitals in Two Regions of Kenya
}

\author{
Simba Milker Atieno ${ }^{1,}{ }^{*}$, Linus Gitonga ${ }^{2}$, Zipporah Ng'ang’a $^{3}$, Patrick Orege ${ }^{4}$ \\ ${ }^{1}$ Faculty of Health Sciences, Jomo Kenyatta University of Agriculture and Technology Nairobi, Kenya \\ ${ }^{2}$ Department of Biological Sciences, Karatina University, Nairobi, Kenya \\ ${ }^{3}$ Department of Medical Laboratory Sciences, Jomo Kenyatta University of Agriculture and Technology, Nairobi, Kenya \\ ${ }^{4}$ Centre for Global Health Research, Kenya Medical Research Institute, Nairobi, Kenya
}

Email address:

Milker24@gmail.com (S. M. Atieno)

*Corresponding author

To cite this article:

Simba Milker Atieno, Linus Gitonga, Zipporah Ng'ang'a, Patrick Orege. Factors Accounting for Differences of Fertility Desires and Intentions Among HIV-Infected and Uninfected Women of Reproductive Age at Six Hospitals in Two Regions of Kenya. International Journal of HIV/AIDS Prevention, Education and Behavioural Science. Vol. 4, No. 1, 2018, pp. 11-19.

doi: 10.11648/j.ijhpebs.20180401.13

Received: June 23, 2018; Accepted: July 29, 2018; Published: August 1, 2018

\begin{abstract}
Previous studies indicate that parenthood is a central life goal in most societies. Child bearing among HIV infected women poses danger of vertical HIV transmission. The study sought to investigate factors accounting for the differences in levels of fertility desires and intentions for HIV-infected and uninfected women of reproductive age from six hospitals in Nyanza and Central regions of Kenya. Intention connotes commitment to a course which usually leads to instrumental behaviors whereas desires are, however, wishes, which may be based more on emotions than on reality. A combination of quantitative and qualitative methods was used. Both HIV-infected and uninfected women desired and intended to have a median of three children. Women from Nyanza were 10.1 times more likely to desire more children than those from Central region $(p<0.001)$. There was significant greater intention to have children among women aged $40-44$ years or older with lower levels of education and living in rural areas. Cultural factors were found to influence fertility desires and intentions among women. To eliminate mother-to-child transmission of HIV, reproductive health interventions should take into consideration the special needs of HIV-infected women to avoid unintended pregnancies, and eliminate the risk of vertical transmission. Additional tailored sexual and reproductive care and counselling support should be provided to HIV- infected women; couples and men to assist them make decisions on issues such as number, spacing and timing of pregnancy and use of contraceptives. Fertility and family planning education should be part of each clinic visit for both female and male HIVinfected clients. More effort should be put on educating male HIV infected clients since male partners have greater influence on fertility intentions in the family in Kenyan society.
\end{abstract}

Keywords: HIV-Infected, HIV-Uninfected, Fertility Desires, Fertility Intentions, Factors Influencing Fertility

\section{Introduction}

Kenya is one of the four HIV high burden countries in Africa [1]. Kenya's HIV prevalence was estimated at 5.9 percent in 2015 with more women (6.5 percent) compared to men (4.7 percent) living with HIV $[2,3]$. Women are more vulnerable to HIV infection compared to men. The epidemic is geographically diverse, ranging from a high prevalence of 26 percent in Homabay County in Nyanza region in western Kenya to a low of approximately $0.4 \%$ in Wajir in the North Eastern region. The high burden of HIV and AIDS in Kenya account for an estimated 29 percent of annual adult deaths, 
20 percent of maternal mortality and 15 percent of deaths in children under age five [1]. HIV prevalence among women is $16 \%$ and $6.2 \%$ in Nyanza and Central regions respectively [4]. Nyanza and Central are contrast regions: Nyanza has the highest HIV burden in the country, high fertility rates, high unmet need of family planning while Central has low HIV burden, while fertility rate is the second lowest after Nairobi at 2.8. In Nyanza the fertility rate is 4.3 with mean number of children ever born to women aged 40-49 years at 5.8, while mean number of children ever born to women aged 40-49 in Central is 3.7 [4]. Total unmet need of family planning is eight point eight percent in Central while Nyanza is at 23.4 percent [4]. The desires and intentions of HIV-infected women to have children is a topic of interest because HIV infection and fertility pose serious challenges in the prevention of HIV, especially mother-to-child transmission and among heterosexual couples. Although Kenya's MTCT rate has dropped from 15.7 percent in 2013 to eight point three percent, it is higher than the global target of $<5 \%$ [5]. Mother-to-child transmission accounts for almost all new infections in children [5]. Without uptake of effective interventions, HIV-infected mothers will continue to infect their children $[6,7,8]$.

Several studies from Nigeria, Kenya, Sub-Saharan Africa and United States have shown that HIV-infected female and male desired to have more children, driven by individual and couple preference as well as societal, religious, cultural expectations such as a desire for sons to carry family name and parenthood as a central life goal [9-12]. Similarly, women on ART in Kenya with HIV status notwithstanding, demonstrated determination to become mothers [13]. This study focuses on factors accounting for the differences of fertility desires and intentions among HIV-infected and uninfected women of reproductive age. Some studies have shown that HIV positive status does not play a significant part on HIV-infected women fertility desire or intentions [1316]. Although Kenya's currently married women have 18 percent of unmet need of family planning services with nine percent in need of spacing and eight percent in need of limiting, there may be a greater unmet need of family planning services among $\mathrm{HIV}$-infected women [4, 17]. Studies in Nigeria, Ethiopia, Uganda and Kenya have shown higher proportion of HIV-positive women being more likely to be associated with unintended (both mistimed and unwanted) pregnancies and a desire not to have more children [18-23].

\section{Methods}

\subsection{Theoretical Framework}

The study used the theory of planned behaviour (TPB) as an analytical framework. This theory proposes that intentions are predictors of human behavior [24]. Further, that these intentions are affected by three blocks of determinants: Firstly, attitudes which are affected by behavioral beliefs and the evaluation of behavioral outcomes. Secondly by the normative components; the beliefs about what others value, expect or accept as affected by gender, cultural norms, education, religious beliefs or socio-economic factors and lastly the degree to control the behavior or the perception of it [25]. The three factors affecting intention are each caused by a set of beliefs, which are determined by factors in the individual's background [25]. Intention connotes commitment to a course which usually leads to instrumental behaviors such as contraceptive use. Desires are, however, wishes, which may be based more on emotions than on reality. A study examining the predictive value of fertility preferences among Ghanaian women indicated that intention to have additional children have shown moderate to strong predictive power [26].

\subsection{Ethics}

Ethical clearance and approval for this study was obtained from the Scientific Steering Committee and the Ethical Review Committee of Kenya Medical Research Institute (KEMRI).

\subsection{Study Population and Inclusion Criteria}

The study was carried out in Nyanza and Central regions of Kenya, six hospitals where the Kenya Mentor Mother Program (KMMP), a peer education and psychosocial support program for PMTCT was being implemented participated in the study. 10 hospitals (nine public and one faithbased) in Nyanza and five hospitals (three public and two faitbased) in Central regions were implementing KMMP at the time of the study. KMMP implementation was initially started at high volume hospitals, this means these hospitals were high volume. The hospitals, Jaramogi Oginga Odinga Teaching and Referral Hospital and Ahero sub-district hospital were randomly selected while Kendu Adventist hospital was purposively selected being the only faithbased hospital among the 10 hospitals implementing KMMP at the time in Nyanza region. In Central Nyeri General hospital, Kiambu district hospital and Nazareth mission hospital were randomly selected to participate in the study. The participants were HIV-infected and uninfected women 15-49 years of age with a known HIV test result. A total of eight health workers from four hospitals, two from each region also participated in the study as Key Informant Interviewees.

The study objectives were explained to the eligible respondents, the right to withdraw at any point of the interview was explained and a written consent was signed. The interviews were carried out with strict confidentiality.

\subsection{The Study Design}

A cross-sectional mixed method study was conducted in October 2011. Quantitative data was collected from HIVinfected and HIV-uninfected women of reproductive age using questionnaires translated into local languages. Qualitative data was collected by focus group discussions (FGDs) with HIV-infected and uninfected women of reproductive age and key informant interviews (KIIs) with 
health workers (clinic nurses/clinical officers) stationed at the comprehensive Care (HIV) clinics and PMTCT clinics at 4 hospitals. Two FGDs were conducted at 2 hospitals in each region, with HIV-infected women (37) and HIV uninfected women (42).

\subsubsection{Sampling Techniques}

The sample size for the quantitative part of the study was calculated by estimating the difference within $95 \%$ confidence interval within $5 \%$ of difference. With an estimated $39 \%$ of married women using modern contraception in Kenya in 2011 [27], the formula [28] to arrive at the minimal sample size was:

$\mathrm{n}=\mathrm{z}^{2} \mathrm{pq} / \alpha^{2}$ (where $\mathrm{z}=1.96, \mathrm{p}=$ proportion of users, $\mathrm{q}=1$ - p, $\alpha=$ allowable error (5\%)

$$
\mathrm{n}=(1.96)^{2} *(0.39) *(0.61) /(0.05)^{2}
$$

$\mathrm{n}=365$ women - applied to for both HIV-infected and HIV uninfected.

$10 \%$ of the total sample $n=365$ was added to both samples (HIV-infected and HIV uninfected) to allow for attrition or refusal during the interview.

\section{Sampling Techniques}

Systematic random sampling was used to select HIVinfected women of reproductive age attending comprehensive care clinic. The number of HIV infected women of reproductive age attending comprehensive care clinic in a given month was used to estimate the population universe from which the desired sample was drawn. The month of October 2011 was randomly selected to form sampling frame (total number of active clients at comprehensive care clinic in the month of October 2011 from the six hospitals). From a sampling frame of 6741, (total HIV-infected women of reproductive age attending comprehensive care clinic at the six hospitals) the sampling interval was determined by dividing the sampling frame by the sample number (6741/402) leading to a sampling interval of 17. From the second HIV-infected client attending clinic and every $17^{\text {th }}$ client were recruited for the study on a daily basis until the desired sample was reached. All participants who took part in the interview on the same day of recruitment were given transport reimbursement of Ksh. 100 (equivalent to USD 1.12 in 2011). HIV-infected clients who agreed to participate in the study but could not be interviewed the same day due to commitment were given appointment to come for the interview on a different date and a transport reimbursement of Ksh. 200 (USD 2.24) was given. Since there was no register for HIV-uninfected women bringing their children at the child welfare clinic, the second and every $17^{\text {th }} \mathrm{HIV}$ uninfected client who came to the clinic was approached to participate in the study. An option of making appointment date or taking the interview the same day was offered. Similarly, a transport reimbursement of Ksh.100 and 200 was given to clients interviewed the same day and those who had appointments respectively. HIV-infected women and HIV uninfected women who had not participated in quantitative study arm were requested to participate in focused group discussion. Health workers for the key informant interviews were purposively selected from the PMTCT clinics and comprehensive care clinics (HIV clinics). Forty five minutes' FGDs were conducted jointly by an experienced nurse trained in qualitative methods and research ethics and the principle investigator in Nyanza region. In Central, FGDs were conducted by two experienced nurses trained in qualitative methods and research ethics. The FGDs were audio-taped, transcribed into local languages and then translated into English. Key informant interviews were conducted for 30 minutes in English. Written informed consent was obtained from each participant prior to individual interview and FGDs.

\subsubsection{Statistical Analysis}

Stata version 13 [29] was used to analyze quantitative data. Chi square and Fishers exact tests were conducted. Statistical tests were evaluated to test significance of associations between dependent and each independent variable at $95 \%$ level of confidence $(\mathrm{P}<0.05)$. The univariable (unadjusted) and multivariable (adjusted) Odds Ratios, 95\% confidence intervals and respective $p$ values were reported. Qualitative data was thematically analyzed. Transcriptions and field notes were analyzed through open coding and grouping codes to categories. From the categories, themes that express content of each group were identified. Finally sifting data, sorting quotes and making comparisons within and between themes were done before data was interpreted.

\section{Results}

The total sample size was 810 , out of which $802(99 \%)$ had indicated their HIV status. $437(54.5 \%)$ were HIVinfected while 365 (45.5\%) were HIV- uninfected. The minimum required sample size was 365 , which was sufficiently met. Statistical power is based on the minimum required sample and it does not affect the analysis by having more observations in one group. The assumption of difference in variance between larger and smaller group does not arise because they are independent samples, each with its own group variability.

Seventy seven point one percent of the respondents were aged below 35 years old. Christian religious affiliation was almost homogenous as shown in Table 1.

Table 1. Socio demographic characteristics of participants by HIV status.

\begin{tabular}{|c|c|c|c|c|c|c|}
\hline Background characteristic & Coding category & $\mathrm{HIV}+\%$ & $\mathbf{n}$ & HIV-\% & $\mathbf{n}$ & p values \\
\hline \multirow[t]{4}{*}{ Age of respondents (years) } & $15-19$ & 3.6 & 434 & 11.1 & 362 & $<0.001$ \\
\hline & $20-24$ & 13.6 & & 30.1 & & \\
\hline & $25-29$ & 29.5 & & 29.6 & & \\
\hline & $30-34$ & 24.7 & & 13.8 & & \\
\hline
\end{tabular}




\begin{tabular}{|c|c|c|c|c|c|c|}
\hline Background characteristic & Coding category & HIV+\% & $\bar{n}$ & HIV-\% & $\bar{n}$ & p values \\
\hline & $35-39$ & 18 & & 7.5 & & \\
\hline & $40-44$ & 7.8 & & 4.7 & & \\
\hline & $45-49$ & 3 & & 3.3 & & \\
\hline \multirow[t]{2}{*}{ Region of residence } & Central & 47.8 & 437 & 48.2 & 365 & 0.912 \\
\hline & Nyanza & 52.2 & & 51.8 & & \\
\hline \multirow[t]{2}{*}{ Place of residence } & Urban & 43.6 & 420 & 41.3 & 361 & 0.517 \\
\hline & Rural & 56.4 & & 58.7 & & \\
\hline \multirow[t]{4}{*}{ Ethnic group } & Kikuyu & 39.7 & 436 & 36.3 & 361 & 0.082 \\
\hline & Luhya & 5.1 & & 9.4 & & \\
\hline & Luo & 48.2 & & 44 & & \\
\hline & Others & 7.0 & & 10.2 & & \\
\hline \multirow[t]{2}{*}{ Religion } & Christian & 97.3 & 433 & 97.5 & 361 & 0.804 \\
\hline & Others & 3.7 & & 2.5 & & \\
\hline \multirow[t]{4}{*}{ Highest level of education } & No formal education & 1.9 & 433 & 0.9 & 352 & $<0.001$ \\
\hline & Primary & 52.4 & & 35.8 & & \\
\hline & Secondary & 34.4 & & 43.2 & & \\
\hline & Post-secondary & 11.3 & & 20.2 & & \\
\hline \multirow[t]{3}{*}{ Employment status } & Formally employed & 15.4 & 415 & 20.6 & 330 & $<0.001$ \\
\hline & Self employed & 59.5 & & 44.6 & & \\
\hline & Housewife & 25.1 & & 34.9 & & \\
\hline \multirow[t]{2}{*}{ Marital status } & Married & 68 & 437 & 74.1 & 363 & 0.057 \\
\hline & Not married & 32 & & 25.9 & & \\
\hline
\end{tabular}

$\mathrm{P}<0.05$ is statistically significant at $95 \%$ level of confidence.

Desire for children among HIV-infected and uninfected women

$\mathrm{HIV}$-infected and Uninfected women in the focus group discussions revealed that childbearing was considered a natural, important and God-given role in a woman's life such that HIV status was not a deterrent. "Mothers without children are not respected, sometimes you may feel left out, you pretend to be happy but within you there is something missing, continuation of generation" (HIV-infected FGD participant). "For me, I think it's a matter of being, for its natural. Because of future, people know that marriage without kids is not complete" (HIV-uninfected FGD participant). Key informant interviews with the health workers also revealed that PMTCT services had positively influenced fertility attitudes by expanding women's choices on contraceptives and majority of the mothers were aware of measures to be taken to avoid infecting infants.

Fear of stigma and inability to care for children due to HIV-related health problems or death was expressed. Similar attitudes were evident in the quantitative results where even though both HIV-infected and HIV- uninfected women reported they may want a child in future, less $(26.4 \%)$ of the HIV-infected than the uninfected $(47.2 \%)$ felt the same, $\mathrm{p}<0.001$ as shown in table 2 .

Table 2. Fertility desire by HIV status.

\begin{tabular}{lll}
\hline \multirow{2}{*}{ Woman's fertility desire } & HIV-infected & HIV-uninfected \\
\cline { 2 - 3 } & Percent $(\mathbf{n}=\mathbf{4 0 1})$ & Percent $(\mathbf{n}=\mathbf{3 2 2})$ \\
\hline I want to have a child right now & 1.7 & 4.7 \\
I want to have a child in the next 2 years & 11.0 & 13.0 \\
I may want a child in the near future & 26.4 & 47.2 \\
I am not sure I would want to have a child in future & 11.0 & 11.2 \\
I don't want to have a child in future & 49.9 & 23.9 \\
Total & 100.0 & 100.0 \\
\hline
\end{tabular}

Factors accounting for differences in desire for children among HIV-infected and uninfected women

The multivariate analysis found that age was positively associated with desire for more children.

Women 35-39 years were 19.8 times more likely to desire more children $(\mathrm{p}<0.001)$ than younger women $<35$ years, while women aged 40-44 years were 32.1 times more likely to desire more children $(\mathrm{p}<0.001)$ than younger women $<40$ years old. A woman from Nyanza region was 10.1 times more likely to desire more children than one from Central region $(\mathrm{p}<0.001)$.

An assessment of the likelihood ratio (LR) indicated that age, region of residence, place of residence, education and employment status were significant in assessing the desire for more children as shown in Table 3.

Table 3. Multivariate analysis of factors accounting for number of children women desire.

\begin{tabular}{|c|c|c|c|c|c|}
\hline Background Characteristics & crude OR $(95 \% \mathrm{CI})$ & crude $P$ & adj. OR $(95 \% \mathrm{CI})$ & P (Wald's test) & P (LR-test) \\
\hline Age in years: ref. $=15-19$ & & & & & $<0.001$ \\
\hline $20-24$ & $1.54(0.32,7.41)$ & 0.587 & $1.65(0.32,8.58)$ & 0.55 & \\
\hline $25-29$ & $3.81(0.88,16.56)$ & 0.074 & $4.9(1.02,23.55)$ & 0.047 & \\
\hline $30-34$ & $4.35(0.98,19.31)$ & 0.053 & $5.92(1.15,30.38)$ & 0.033 & \\
\hline
\end{tabular}




\begin{tabular}{llllll}
\hline Background Characteristics & crude OR (95\%CI) & crude P & adj. OR (95\%CI) & P (Wald's test) & P (LR-test) \\
\hline $35-39$ & $6.84(1.54,30.44)$ & 0.012 & $19.88(3.69,106.95)$ & $<0.001$ & \\
$40-44$ & $8.62(1.81,41.18)$ & 0.007 & $32.15(5.41,191.03)$ & $<0.001$ & \\
45-49 & $4.6(0.7,30.19)$ & 0.112 & $12.4(1.34,114.59)$ & 0.026 & \\
Residence: Nyanza vs. Central (ref.) & $5.14(2.94,9)$ & $<0.001$ & $10.12(4.99,20.54)$ & $<0.001$ & $<0.001$ \\
Place: Urban vs. Rural (ref.) & $0.41(0.25,0.66)$ & $<0.001$ & $0.48(0.27,0.85)$ & 0.012 & 0.01 \\
Level of Education: ref.=No Education & & & & $<0.001$ \\
Primary & $0.72(0.18,2.85)$ & 0.638 & $0.53(0.1,2.81)$ & 0.453 & \\
Secondary & $0.15(0.04,0.64)$ & 0.01 & $0.13(0.02,0.73)$ & 0.021 & \\
Post-Secondary & $0.15(0.03,0.71)$ & 0.017 & $0.24(0.04,1.61)$ & 0.143 & \\
Employment Status: ref.=Formally employed & & & & \\
Self employed & $4.32(1.82,10.24)$ & $<0.001$ & $3.87(1.38,10.89)$ & 0.01 & \\
House wife & $3.07(1.23,7.66)$ & 0.016 & $2.31(0.76,6.98)$ & 0.138 & \\
Marital Status: ref.=Married & & & & \\
Single & $0.31(0.14,0.7)$ & 0.004 & $0.47(0.2,1.11)$ & 0.086 & \\
Divorced & $1.9(0.2,18.56)$ & 0.579 & $1.2(0.03,47.23)$ & 0.922 & \\
Separated & $1.22(0.34,4.37)$ & 0.755 & $1.09(0.24,5.04)$ & 0.911 & \\
Widowed & $3.2(1.59,6.44)$ & 0.001 & $1.43(0.6,3.41)$ & 0.424 & \\
HIV Status: Negative vs. Positive (ref.) & $0.62(0.4,0.97)$ & 0.038 & $1.36(0.78,2.4)$ & 0.279 & \\
\hline
\end{tabular}

$\mathrm{P}<0.05$ - Statistically significant at $95 \%$ level of confidence.

Factors accounting for differences in the number of children women intend to have

The results show that a woman living in an urban area was 0.29 times more likely to intend to have more children than one in a rural area $(\mathrm{p}<0.001)$. An assessment of the likelihood ratio (LR) showed that woman's age, region, place of residence and education $(\mathrm{p}<0.001)$ and marital status $(\mathrm{p}=$ 0.038 ) have a significant difference in assessing the women's fertility intentions as shown in Table 4.

Table 4. Factors accounting for number of children a woman intends to have.

\begin{tabular}{|c|c|c|c|c|c|}
\hline Background Characteristics & crude OR $(95 \% \mathrm{CI})$ & crude $P$ value & adj. OR (95\%CI) & P (Wald's test) & P (LR-test) \\
\hline Age: ref. $=20-24$ years & & & & & $<0.001$ \\
\hline $15-19$ [no data] & - & - & - & - & \\
\hline $25-29$ & $3.78(1.26,11.3)$ & 0.017 & $4.43(1.41,13.86)$ & 0.011 & \\
\hline $35-39$ & $9.27(3.06,28.11)$ & $<0.001$ & $18.65(5.22,66.61)$ & $<0.001$ & \\
\hline $40-44$ & $18.62(5.75,60.3)$ & $<0.001$ & $63.56(15.78,256.06)$ & $<0.001$ & \\
\hline $45-49$ & $4.34(0.74,25.62)$ & 0.105 & $8.65(1.18,63.66)$ & 0.034 & \\
\hline Place: Urban vs. Rural (ref.) & $0.29(0.16,0.52)$ & $<0.001$ & $0.32(0.16,0.63)$ & 0.001 & $<0.001$ \\
\hline Level of Education: ref.=No Education & & & & & $<0.001$ \\
\hline Primary & $1.82(0.22,14.82)$ & 0.577 & $2.6(0.24,28.65)$ & 0.434 & \\
\hline Secondary & $0.42(0.05,3.61)$ & 0.429 & $0.66(0.06,7.6)$ & 0.736 & \\
\hline Post-Secondary & $0.08(0,1.39)$ & 0.083 & $0.22(0.01,5)$ & 0.343 & \\
\hline Employment: ref.=Formally employed & & & & & 0.108 \\
\hline Self employed & $4.55(1.6,12.9)$ & 0.004 & $3.03(0.91,10.11)$ & 0.072 & \\
\hline House wife & $3.54(1.19,10.57)$ & 0.024 & $3.52(0.97,12.78)$ & 0.056 & \\
\hline Single & $0.31(0.12,0.79)$ & 0.014 & $0.41(0.14,1.16)$ & 0.093 & \\
\hline Divorced & $2.63(0.27,25.73)$ & 0.406 & $1.62(0.01,420.83)$ & 0.866 & \\
\hline Widowed & $3.21(1.51,6.84)$ & 0.002 & $1.55(0.62,3.88)$ & 0.344 & \\
\hline HIV Status: Negative vs. Positive (ref.) & $0.59(0.35,0.99)$ & 0.044 & $1.39(0.73,2.65)$ & 0.312 & 0.313 \\
\hline
\end{tabular}

$\mathrm{P}<0.05$ is statistically significant at $95 \%$ level of confidence.

\section{Discussion}

The study showed that similar factors contributed to desire and intention for HIV-infected and uninfected women. Factors including; region of residence, place of residence (urban vs rural), age, education and employment status were significant in assessing the desires and intentions for children among HIV-infected and uninfected women while marital status was a significant factor for fertility intentions regardless of HIV status. This is consistent with qualitative findings of this study in both regions which indicated that women are driven by cultural norms and cultural expectations of women's role in the society, as in the quote from HIV-infected woman focused group discussion (FGD) participant from Central region; "Women without children are not respected. Marriage brings that desire to have a child, continuation of generation. It is one of the qualifications to be called a mother." Studies carried out in Kenya and South Florida indicate that fertility intention among HIV-infected women is barred by interplay of sociodemographic, sociocultural and relationship issues such as desire for sons and ability to carry on the family name, value placed on children 
by women and their community's social norm including partner fertility desire $[10,14,30]$. Depending on the pressure brought about by cultural factors, most HIV-infected women may want to achieve their fertility desires and intentions regardless of their status and health condition. It is necessary that as health workers engage with HIV-infected women they should aim at creating a relationship where the health worker and HIV-infected woman can talk freely to enable the woman make decisions that are not harmful to themselves and others. Health workers need to improve how they engage with HIV-infected clients knowing that children are highly valued in most African communities.

Some studies have shown that the use of ART was significant predictor in fertility intentions while Fertility intention has been shown to provide a fairly accurate forecast of fertility behaviour in Malaysia [31, 32]. Given the argument above it is important that health workers attending to HIV-infected women and couples identify their fertility intentions and tailor sexual and reproductive care and counselling to assist women in making decisions on issues such as number, spacing and timing of pregnancies, and use of contraceptives methods. There is international consensus that the goal of preventing mother-to-child transmission of HIV (PMTCT) cannot be met without increasing access to family planning services. Offering integrated HIV and Sexual and Reproductive Health (SRH) services is considered an effective means to manage and deliver care for HIV-infected women. Integration of SRH and HIV services has the potential to simultaneously address multiple patient needs in one location [32, 33, 34]. The Ministry of Health should ensure that HIV and SRH services are integrated, to enable effective use of these services. HIV-infected women attending antenatal clinic for PMTCT services should be provided with SRH services in the same place and those attending HIV clinics should also get SRH services at the same place. HIV infected women may still suffer from perceived health worker or self-stigma which may prevent them move from one service point to another where they may need to disclose their status over and over again.

The predominant ethnic groups for this study were Kikuyu from Central region, and Luo from Nyanza region. The latter was found to have higher fertility desires. These findings are consistent with other studies on fertility in sub-Saharan Africa and Kenya showing that cultural norms and ethnic controls may encourage or discourage high fertility while the influence of early education and colonization indicate least preference for large families [35, 36, 37]. This is contrary to KDHS, 2014 showing that Nyanza had the highest number of women with secondary education at seven percent, with Central region coming third with five percent while the distribution of higher education was only one percent in each region. Cultural factors affect even the learned and one has to be very strong and well convinced with facts on a particular issue to go against the cultural norms. Cultural norms may be stronger among Luos than Kikuyus. It is only effective education tailored to a HIV-infected woman's needs that may bring rational thinking for effective decision-making.
Although it is generally known that social context of urban areas accelerates adoption of new reproductive behaviour, the study indicated that a woman (HIV infected and HIVuninfected) living in urban area was 0.29 times more likely to intend to have more children than one in rural area contrary to findings from latest KDHS, 2014 where total fertility rate in urban is lower than rural at 3.1 and 4.5 respectively, this is validated by another study in Kenya. However, another study in sub-Saharan Africa has shown that modern contraceptives use has increased more among rural than urban women in both Ghana and Kenya. Although in terms of demographic factors, poor, uneducated and rural Kenyan women have high TFRs, low contraceptive use and high unmet need for contraceptives, in comparison with other groups in both countries [4, 36, 38]. While a study on urban and rural fertility transitions in developing world indicated that national definitions of rural and urban may change over time, as the boundaries tend to move out into formerly rural areas as urban populations sprawl but also since urban/rural status of the previous residence is self-reported, and thus subject to even larger biases [39], it is not clear if this unexpected finding could have been as a result of any of the factors mentioned. A further study to explore this finding is necessary.

Qualitative results from this study indicated that despite HIV status, women desire and intend to have children as a matter of priority. In response to a question why women desire children, participants concluded that "Mothers without children are not respected. Sometimes you may feel left out. You can pretend to be happy but within you there is something missing. It is continuation of generation." (HIVinfected FGD participant). These findings are similar to studies from Kenya, and Ethiopia which have reported that HIV does not negatively modify women's subsequent fertility intentions. On the contrary use of ART has been noted to significantly predict fertility intention as having children is considered a prerequisite for a happy and fulfilled life $[13,32]$. However other studies from South Africa and Mozambique have shown that HIV-infected pregnant women are more likely than HIV-uninfected women to have maternal morbidity, poor pregnancy and neonatal outcomes [40, 41]. It is therefore important that HIV-infected women get adequate health education and counselling support on fertility and sexual and reproductive health to empower them to make informed choices. Fertility and sexual and reproductive health should include men and couples attending clinics as studies have reported that men play an important role in decision-making in the home in many African contexts, and male fertility desires and participation in child-bearing decisions can have crucial impact on the woman [20]

In this study older HIV-infected and uninfected women 35-39 years were 18.6 times more likely to desire more children while women aged 40-44 were 32.1 times more likely to desire more children than younger women. This unexpected finding as women at 40 years and above are considered older enough to have completed child bearing, however it may be due to the need to replace if they have had HIV -infected children or lost 
children due to HIV. The introduction of more efficacious ART to prevent mother-to-child transmission of HIV has improved maternal and neonatal health outcomes which may appeal to an HIV-infected mother who would want to have (a)another child but in this study it was both HIV-infected and uninfected women. Further research is needed to explore what may be the reasons for this.

In relation to education, the higher the level of education attainment of a woman, the lower the chances of desiring to bear more children. This is in contrast to findings of KDHS 2014 where women in Nyanza have the highest level of secondary education but had higher fertility desires in this study. It is noteworthy that Central because of its proximity to the capital city of Kenya and good weather for agriculture is far richer than Nyanza and more parents can afford to take their children to schools. Contraceptive uptake is also higher in Central and by assumption fewer girls should drop out of school due to pregnancies. In contrast, Nyanza has the highest rate of teenage pregnancies associated with lack of education, as well as partner violence among teen girls which are more important public health issues [8]

This shows that fertility desire and intention is influenced by several complex factors that can best be explained by Theory of Planned Behaviour (TPB) to include attitude, subjective norm and perceptions of behavioural control. The study has shown from qualitative data, that beliefs and cultural norms have a big influence on fertility, what is not clear is if the perception of behavioural control can be considered effective in cases where HIV infected women plan not to have pregnancy but do not use any contraceptive method. Occurrence of an unintended birth for example is more likely due to ineffective actual behavioural control than to rationality issues [42]. Health workers education and counselling support to women on matters fertility and contraceptives is therefore very important for development of effective behavioural control. Findings from this study indicated that women were not getting adequate client education from health workers. In response to a question, if in their opinion both HIV infected and uninfected women were getting adequate information to manage their reproductive health needs, both groups indicated they were not getting adequate information as quoted; "there is insufficient information from health workers. We are lucky (HIV-Infected women) because we have Mentor Mothers" (HIV-Infected woman FGD participant). "I think HIV positive women get enough support because they have support groups. When I gave birth to my first baby, it was so difficult, my breast were swollen and I did not know what to do, I wished there was a session where women can meet and learn from each other about women issues" (HIV uninfected woman FGD participant). Another study from Uganda found that, patients do not feel comfortable communicating their desires with providers, effectively preventing an opportunity to learn about options for safer contraception and limiting risks of horizontal transmission [43].

Health workers should take into consideration that HIVinfected women need special attention to overcome barriers that may influence adherence to PMTCT services for the good of their own health, that of their unborn children and sexual partners [44]. In the context of acute shortage of health workers hence inadequate time with HIV-infected client attending care, task-shifting of non-clinical tasks such as SRH education to lay health workers such as Mentor Mothers should be considered.

\section{Conclusion}

This study has shown that HIV positive status does not deter women from desiring and intending to have children. To eliminate mother-to-child transmission, reproductive health interventions should take into consideration the special needs of HIV-infected women to help them avoid unintended pregnancies, protect themselves and their partners from further infections, and eliminate the risk of vertical HIV transmission. In order to harness the benefits of utilization of HIV and Sexual and Reproductive Health (SRH) services offered in an integrated manner, these intervention programs should target the geographic regions of the country that are less likely to utilize the latter services and tailor sexual and reproductive care and counseling services to meet different women's needs and assist them make decisions on issues such as number, spacing and time of pregnancy and use of contraceptives safely. Education, age of a woman and marital status are also important considerations for effective HIV and SRH integrated service delivery. It is important to be aware that even mature women of 40 years and above may still have desire and intention to have children and health care workers should ensure that all women attending routine HIV clinic regardless of their education and age should have an opportunity to information on fertility and SRH through education tailored to their needs and unique circumstances.

\section{Disclaimer}

The views expressed in this article are the authors and not an official position of the institution.

\section{Declaration of Conflicting Interests}

There was no conflict of interests related to this study.

\section{Funding}

The research received no specific grant from any funding agency in public, commercial or not for profit sectors.

\section{References}

[1] Kenya HIV County Profile, (2016). Accessed on 28/4/2018 (http://nacc.or.ke/wp-content/uploads/2016/12/Kenya-HIVCounty-Profiles-2016.pdf?)

[2] National AIDS and STI Control Program (NASCOP) and National AIDS Control council (NACC). (2016). Kenya HIV Estimates Report, 2015. Nairobi: Ministry of Health. (http://nacc.or.ke/wp-content/uploads/2016/12/Kenya-HIVEstimates-2015.pdf) 
[3] UNAIDS, (2016) Country Fact sheet (http://www.unaids.org/en/regionscountries/countries/kenya

[4] National Bureau of statistics and ICF International, (2015). 2014 KDHS Key findings. Rockville, Maryland USA: KNBS and ICF International (https://www.dhsprogram.com/pubs/pdf/sr227/sr227.pdf)

[5] NACC. Kenya AIDS Response Progress Report, 2016. Nairobi: Ministry of Health, (http://nacc.or.ke/wpcontent/uploads/2016/11/Kenya-AIDS-Progress-

Report_web.pdf)

[6] Kyomuhendo S. and Kiwanuka, J. (2008). Access to care, treatment and sexual and reproductive health rights and needs of HIV positive women in Masindi and Busia districts, Uganda. International Community of Women Living with HIV/AIDS Eastern Africa Region.

[7] Mwau M. Bwana P. Kithinji L. et al (2017). Mother- to- Child transmission of HIV in Kenya: A cross-sectional analysis of national data base over 9 years, PLOS ONE; 12(8): doi 10. 1371/journal.pone. 0183860 .

[8] Jobanputra K, Parker LA, Azih C, Okello V, Maphalala G, Kershberger B, et al. (2015). Factors associated with virological failure and suppression after enhanced adherence counselling, in children, adolescents and adults on antiretroviral therapy for HIV in Swaziland. PLoS One; 10(2):e0116144. pmid:25695494

[9] Oladapo OT, Olusoji JD, Odusoga OL et al. (2005). Fertility desires and intentions of HIV-infected patients at a suburban specialist centre. Journal of the National Medical Association. 12: 1672-1682. 7.

[10] Withers M, Dworkin S, Harrington E, et al. (2014). Fertility intentions among HIV-infected, sero-concordant Kenyan Couples in Nyanza province, Kenya. Journal of Culture Health Sexuality. 15(10): 10. 1080/13691058. 2013. 811289.

[11] Becker G and Nacthigall RD. (1994). Born to be a mother: the cultural construction of risk in infertility treatment in the US. Social Science Medicine. 39: 507-518.

[12] Guthrie Bl, deBruyn G and Farquhar C. (2007). HIV-1discordant couples in sub-Saharan Africa: explanations and implications for high rates of discordancy. Current HIV Research. 4: 416-429.

[13] Ujiji OA, Ekstrom AM, Ilako F. et al. (2010). I will not let my HIV-status stand in the way: decisions on motherhood among women on ART in a slum in Kenya. BMC Women's Health. 133.

[14] Ayieko J, Ti A, Hagey J, Akama E, Bukusi EA, Cohen GR and Patel RC. (2016). HIV status and Treatment Influence on Fertility desires among Women newly becoming eligible for Antiretroviral Therapy in Western Kenya: Insights from a Qualitative study. BMC Reproductive Health.

[15] Kebogile M \& Yenealem RB (2017) Fertility intention and use of contraception among women living with the human immunodeficiency virus in Oromia Region, Ethiopia, South African Family Practice, 59:1, 46-51, DOI: 10. 1080/20786190. 2016. 1254931.

[16] Ashimi A O, Amole T G, Abubakar M Y, Ugwa E A. Fertility desire and utilization of family planning methods among HIV-positive women attending a tertiary hospital in a suburban setting in Northern Nigeria. Trop J Obstet Gynaecol [serial online] 2017 [cited 2018 Jul 4]; 34: 5460. Available from: http://www.tjogonline.com/text.asp?2017/34/1/54/207095

[17] Mayhew SH, Colombini M, Kimani JK, et al (2017). Fertility intentions and contraceptive practices among clinic-users living with HIV in Kenya: a mixed methods study BMC Public Health. 2017; 17: 626. doi: 10. 1186/s12889-017-45142.

[18] Kimani J, Warren C, Abuya T Mutemwa R et al. (2015). Family planning use and fertility desires among women living with HIV in Kenya. BMC Public Health; 15: 909. doi: 10. 1186/s12889-015-2218-z.

[19] Ngugi EW, Kim AA, Nyoka R, N'gan'ga L, et al. (2014). Contraceptive Practices and Fertility Desires Among HIVInfected and Uninfected Women in Kenya: Results from a Nationally Representative Study. Journal of Acquired Immune Deficiency Syndrome. Volume 66, supplement 1.

[20] Gutin SA, Namusoke F, Shade SB, \& Mirembe F. (2014). Fertility Desires and Intentions among HIV -positive Women during Post-natal period in Uganda. African Journal of Reproductive Health; 18(3): 67.

[21] Wekesa \& Coast E. (2015). Contraceptive Need and Use among Individuals with HIV/AIDS Living in the slums of Nairobi Kenya. Journal of Gynecology and Obstetrics 130, E31-E36.

[22] Oyebode T, Sagay A, Musa J, Ekwempu C, Agaba P, Idoko J, Okonkwo P, Kanki P. Unmet need for contraception among human immunodeficiency virus-positive women in Jos, Nigeria: A call to integrate family planning and human immunodeficiency virus services. J HIV Hum Reprod 2016;4:13-9

[23] Abeje G. \& MotbaynorA. (2016). Demand for family planning among HIV positive women on ART: the case of South Gondar and North Wollo Zones Amhara region, BMC Res Notes 2016; 9:43. Doi: 10. 1186/s13104-016-1850-8.

[24] Ajzen I. (2005). Attitudes, personality, and behavior. 2nd ed. Maidenhead, Berkshire, England: Open University Press.

[25] Ajzen I. (1991). The theory of planned behavior. Organizational Behavior and Human Decision Processes. 50: 179-211.

[26] Ivy, AK, David R. J. \& Johson, BC. (2010), Examining the predictive value of fertility preferences among Ghanaian women. Demographic Research. 2010; 22: 965-984. doi: 10. 4054/DemRes. 22. 30.

[27] KNBS, Kenya. Kenya Demographic and Health Survey 200809. (, 2009). Preliminary Report, Calverton, Maryland: KNBS, NACC, NASCOP, NPHLS, KEMRI, NCAPD, ICF Macro. (https://dhsprogram.com/pubs/pdf/fr229/fr229.pdf)

[28] Cochran WG. (1963.). Sampling Techniques. 2nd ed. New York: John Wiley and Sons,

[29] StataCorp. 2013. Statistical Software: Release 13. College Station, TX: StataCorp LP

[30] Jones DL Cook R. Potter JE Shatz MT et al (2016). Fertility Desires among Women Living with HIV. PLoS One. 2016; 11(9): e0160190. doi: 10. 1371/journal. pone. 0160190

[31] Tan PC, \& Tey NP. (1994). Do Fertility Intentions Predict Subsequent Behaviour? Evidence from Peninsular Malaysia: Studies on Family Planning. 
[32] Mekonnen H, Enquselassie F (2017) Effect of antiretroviral therapy on changes in the fertility intentions of human immunodeficiency virus-positive women in Addis Ababa, Ethiopia: a prospective follow-up study. Journal of Epidemiology and Health; 39: e2017028. DOI: https://doi.org/10.4178/epih.e2017028

[33] Rutaremwa G, \& Kabagenyi A. (2016). Utilization of Integrated HIV and Sexual and Reprodictive Health Services among Women in Uganda. BMC Health Services Research. https://doi.org/10.1186/s12913-016-1761-3

[34] UNFPA. (2004). The Glion Call to Action on Family Planning and HIV/AIDS in Women and children. New York. Available at http://www.who.int/hiv/pub/advocacymaterials/glionconsultati onsummary-DF pdf

[35] Caldwell JC and Caldwell P. (1987). The cultural context of high fertility in sub-Saharan Africa. Population and Development Review. 13: 409-437.

[36] Fapohunda BM, \& Poukouta P. V. (1997). Trends and Differentials in Desired Family Size in Kenya. African Population Studies: 12 (1)

[37] Kalule-Sabiti (1992) Socio-economic factors affecting fertility in Kenya, South African Journal of Sociology, 23:2, 46-52, DOI: 10. 1080/02580144. 1992. 10429816

[38] "3 Trends in Reproductive Behavior." National Academies of Sciences, Engineering, and Medicine. (2016). Recent Fertility Trends in Sub-Saharan Africa: Workshop Summary. Washington, DC: The National Academies Press. doi: 10. $17226 / 21857$.
[39] Lerch M. (2017). Urban and Rural Fertility Transitions in developing World: A cohort perspective. Max Planck Institute for Demographic Research; MPIDR Working Paper.

[40] Bodkin C, Klopper H and Langley G. (2006). A comparison of HIV positive and negative pregnant women at a public sector hospital in South Africa. Journal of Clinical Nursing; 6: 735-741.

[41] Gonzalez R, Ruperez M, Sevene E, Vala A, Maculuves S, Bulo H et al. (2017). Effects of HIV infection on maternal and neonatal health in Sourthern Mozambique: A prospective cohort study after a decade of antiretroviral drugs roll out. PLOS ONE.

[42] Barber JS. (2011). Theory of Planned Behaviour: Considering Drives, Proximity and Dynamics. Vienna Yearbook of Population Research, 9, 31-35. Doi: 10. 1553/population yearbook 2011s31

[43] Wagner G J. and Wanyenze R. (2013). Fertility Desires and Intentions and the Relationship to Consistent Condom Use and Provider Communication regarding Childbearing among HIV Clients in Uganda. Infectious Diseases. Volume 2013, Article ID 478192, 7 pages. http://dx.doi.org/10.5402/2013/478192

[44] Chen JL, Philips KA Kanouse DE et al. (2001). Fertility desires and intentions of HIV-infected men and women. Family Planning Perspectives; 13: 144-152. 